\title{
"SEJÃO QUAES FOREM OS SACRIFÍCIOS, REGENER-SE A INSTRUCÇÃO": A INSTRUÇÃO NA PROVINCIA DA PARAHYBA DO NORTE NO RELATÓRIO DE DIOGO VELHO CALVALCANTI D' ALBUQUERQUE (1861)
}

\author{
Cristiano de Jesus Ferronato ${ }^{1}$, Viviane Vieira Santos Matos ${ }^{2}$, Ane Luise Silva Mecenas Santos ${ }^{3}$ \\ ${ }^{1}$ Doutor em Educação pela Universidade Federal da Paraíba - UFPB, João Pessoa, PB. Atualmente é docente \\ permanente do Programa de Pós-Graduação em Educação da Universidade Tiradentes - UNIT, Pesquisador do \\ Instituto de Tecnologia e Pesquisa-ITP. Aracaju, SE. E-mail: cristianoferronato@gmail.com \\ ${ }^{2}$ Mestranda do Programa de Pós-Graduação em Educação da Universidade Tiradentes - UNIT, Aracaju, SE. É bolsista \\ do PROCAPS/FAPITEC/UNIT. E-mail: elizagleizersantos1@ hotmail.com \\ ${ }^{3}$ Doutora em História pela Universidade do Vale do Rio dos Sinos - UNISINOS. Atualmente, realiza o pós- \\ doutoramento junto ao Programa de Pós-Graduação em Educação da Universidade Tiradentes - UNIT, como bolsista \\ PNPD-CAPES, Aracaju, SE .E-mail: anemecenas@ gmail.com
}

\section{RESUMO}

O presente texto busca discutir a forma como a educação brasileira nos Oitocentos, especialmente na Província da Parahyba do Norte, era tratada pelos governantes da Província. A análise estruturou-se a partir da crítica documental aos Relatórios do Diretor da Instrução Pública naquela Província, elaborados por Diogo Velho Cavalcanti d' Albuquerque, encaminhados à Assembleia Provincial no ano de 1861. Como parte do trabalho do historiador, o cotejo com outras fontes possibilitou a melhor compreensão acerca das práticas educacionais do referido período, das quais destaca-se a legislação educacional em vigor no período. Para a construção deste trabalho, foi fundamental o diálogo com a bibliografia referente ao período, dentre elas podemos citar Matos (1987), Gondra e Schneider (2011), Ferronato (2012; 2015) e Faria Filho (2016).

Palavra chave: História da educação. Parahyba do Norte. Leis e regulamentos. Diretoria da Instrução Pública.

\section{"BE WHAT THE SACRIFICES ARE, REGENERATE THE INSTRUCTION": THE INSTRUCTION IN THE PROVINCE OF PARAHYBA DO NORTE IN THE REPORT OF DIOGO VELHO CALVALCANTI D 'ALBUQUERQUE (1861)}

\begin{abstract}
The present text seeks to discuss how the Brazilian education in the Eighth, especially in the Province of Parahyba do Norte, was treated by the rulers of the Province. The analysis was structured from the documentary criticism to the Reports of the Director of Public Instruction in that Province, elaborated by Diogo Velho Cavalcanti d 'Albuquerque, sent to the Provincial Assembly in the year 1861. As part of the work of the historian, the comparison with other sources made possible the better understanding about the educational practices of the period, of which the educational legislation in force in the period stands out. For the construction of this work, it was fundamental the dialogue with the bibliography referring to the period, among them we can mention Matos (1987), Gondra and Schneider (2011), Ferronato (2012; 2015) and Faria Filho (2016).
\end{abstract}

Keyword: History of education. Parahyba do Norte. Laws and Regulations. Board of Public Instruction.

\section{"SEAN CUALES SON LOS SACRIFICIOS, REGENERSE LA INSTRUCCIÓN": LA INSTRUCCIÓN EN LA PROVINCIA DE LA PARAHYBA DEL NORTE EN EL INFORME DE DIOGO VELHO CALVALCANTI D 'ALBUQUERQUE (1861)}

\section{RESUMEN}

El presente texto busca discutir la forma como la educación brasileña en los ochocientos, especialmente en la provincia de Parahyba del Norte, era tratada por los gobernantes de la Provincia. El análisis se estructuró a partir de la crítica documental a los Informes del Director de la Instrucción Pública en aquella Provincia, elaborados por Diogo Velho Cavalcanti d 'Albuquerque, encaminados a la Asamblea Provincial en el año 1861. Como parte del trabajo del historiador, el cotejo con otras fuentes posibilitó la mejor comprensión 
acerca de las prácticas educativas de dicho período, de las cuales se destaca la legislación educativa en vigor en el período. Para la construcción de este trabajo, fue fundamental el diálogo con la bibliografía referente al período, entre ellas podemos citar Matos (1987), Gondra y Schneider (2011), Ferronato (2012, 2015) y Faria Filho (2016).

Palabras Clave: Historia de la educación. Parahyba del Norte. Leyes y reglamentos. Dirección de la Instrucción Pública.

\section{INTRODUÇÃO}

O trabalho muitas vezes solitário do pesquisador é inserido numa rede maior graças ao constante diálogo com a bibliografia especializada, como também pela constituição de grupos voltados a construção sistemática de textos e preocupados com o acesso às fontes. A publicização do pensamento científico em diferentes suportes permite aos estudiosos mapear outros limites geográficos ao longo do tempo, além de evidenciar as semelhanças e distinções das práticas educacionais no território nacional.

Ao longo das últimas décadas as pesquisas realizadas no âmbito da História da Educação têm buscado revisitar documentos já conhecidos, com novos problemas, como também a sistematização de acervos que permitam lançar novos olhares acerca do campo. A digitalização de fontes, organização de catálogos, a manutenção de instituições arquivísticas e a constituição de novos acervos possibilita o aprofundamento empírico do conhecimento, o cotejo com diferentes tipologias documentais e o acesso às fontes. Essa pesquisa se tornou possível, graças a documentação sistematizada e digitalizada, disponível no site da Sociedade Brasileira de História da Educação (SBHE).

Este texto tem o objetivo de discutir como as questões relativas à organização da instrução pública na Província da Parahyba do Norte, foram abordadas pelo Diretor do referido setor naquela Província no ano de 1861, Diogo Velho Cavalcanti $d$ ' Albuquerque. Para tanto, procedeu-se à análise do Relatório da Diretoria da Instrução Pública, encaminhado à Assembléia Provincial, anexo ao Relatório do Presidente da Província, o Dr. Luiz Antônio da Silva Nunes, naquele ano. Os Relatórios dos Presidentes da Província, doravante denominados apenas Relatórios, constituem-se um importante tipo de documento oficial do período provincial, tendo em vista a facilidade de sua consulta.
Estes relatórios eram elaborados no sentido de atender à exigência contida em um Aviso Circular Imperial, do ano de 1848, que determinava que todo ocupante do cargo de presidente da Província tinha o dever de, no início de cada ano, apresentar à Assembleia provincial uma mensagem ou exposição prestando contas da situação da Província no ano anterior. Dentre os assuntos abordados nos Relatórios, a instrução na Província tinha grande destaque, descrevendo a situação das diversas aulas avulsas de ensino secundário e as aulas de primeiras Letras criadas pelo governo provincial e fornecendo informações relativas ao investimento financeiro neste ramo, salário de professores, métodos, quadros estatísticos registrando o número de alunos, professores e escolas de toda a Província entre outros temas.

Nesse sentido, temos que os principais acontecimentos relevantes em relação à instrução pública das Províncias brasileiras nos Oitocentos, encontram-se registrados em diversas fontes como revistas, jornais, folhetos e documentos oficiais da época como relatórios dos Presidentes de Províncias. Junto aos Relatórios dos Presidentes de Províncias eram anexados os vários relatórios dos outros setores da administração pública, como saúde, segurança, obras e instrução.

Para esta análise delimitamos como objeto a instrução na Província da Parahyba do Norte, a partir do estudo do relatório do Diretor da instrução pública Diogo Velho Calvalcanti $d^{\prime}$ Albuquerque, anexo ao relatório do presidente de Província Dr. Luiz Antônio da Silva Nunes e apresentado à assembleia no ano de 1861. Enquanto historiadores da educação entendemos os Relatórios dos Presidentes da Província e, principalmente, aqueles assinados pelos Diretores da instrução pública como um importante tipo de documento oficial do período Imperial brasileiro, tendo em vista a diversidade dos assuntos de que tratam, e principalmente por termos mesmo que de forma oficial uma visão da 
organização e dos problemas enfrentados pela instrução nas Províncias brasileiras, distantes da Corte Imperial.

Como afirmamos anteriormente, segundo a legislação em vigor no período, todo ocupante do cargo de presidente da Província e suas diretorias tinham o dever no início de cada ano e no fim de seu mandato de apresentar uma exposição da situação da Província nos vários setores. Segundo Faria Filho e Resende (2001),

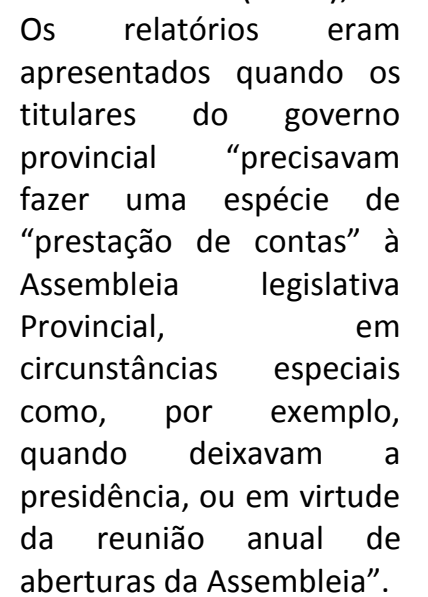

O presente trabalho abordará, portanto, a questão relacionada à instrução na Província da Parahyba do Norte, na visão do referido Diretor. Tendo em vista tais questões, foi de fundamental importância consultar autores que nos forneceram uma base teórica para que a presente pesquisa pudesse se apoiar, como Matos (1987), Saviani (2007), Gondra e Schneider (2011), Ferronato $(2012$; 2015) e Faria Filho (2016), que dão contribuições sobre o período abordado e aos temas relacionados.

Segundo Matos (1987), a construção de poder da autoridade foi uma das características do Estado Imperial. A sociedade dirigente fundamentou-se para esse imaginário de Nação em princípios da hierarquização, disciplina e civilização. A política administrativa no período imperial, principalmente no que tange à instrução pública ficou bem clara na publicação do Ato adicional de 1834, que delegou às Províncias o poder de legislar sobre este tema no que se referia às primeiras letras e ao ensino secundário, ficando a Corte responsável por legislar unicamente sobre o ensino superior.

Nessa perspectiva, pretende-se neste texto trazer à luz alguns dos temas e preocupações com relação à instrução pública na Província da Parahyba do Norte relatadas pelo Diretor em seu relatório no ano de 1861, um homem que teve uma atuação muito importante no que tange ao jogo da política imperial do século XIX, chegando aos mais altos cargos da hierarquia imperial e nobiliárquica, visto que ostentou o título de Visconde de Cavalcanti.

\section{Instrução pública: Organização uniforme sobre uma direção central \\ Antes de adentrarmos à análise} propriamente do referido relatório entendemos ser importante apresentarmos o Diretor da Instrução Pública da Província da Parahyba do Norte, autor do mesmo. No intuito de mapear o lugar social de Diogo Velho Cavalcanti d'Albuquerque e, dessa forma, identificar os indícios dos posicionamentos adotados na compreensão das questões de instrução política presentes no referido relatório.

Em 1861, o então Diretor de instrução pública da Província da Parahyba do Norte, diante das características que apresentavam a elite brasileira, já havia passado por várias esferas políticas, entre elas, a Assembleia Provincial, no biênio de 1854-1855, como membro do Partido Conservador, também foi representante da Parahyba na Câmara dos Deputados para a legislatura de 1857-1860. Entre o período de $1857 / 60$ foi morar na cidade do Rio de Janeiro, quando foi convidado a ser um dos membros do gabinete presidido pelo Visconde de Itaboraí. Foi nomeado Presidente da Província do Piauí em 1859, Diretor de Instrução Pública da Província da Paraíba em 1861-1862, Presidente das Províncias da Ceará, em 1868, e de Pernambuco, em 1870.

Fazendo parte do grupo seletivo, ou como denominou José Murilo de Carvalho no livro A construção da ordem e teatro de sobras (1996) o "Clube do Imperador", ele alçou aos mais altos cargos da elite imperial. Destes destacam-se, Ministro da Agricultura, Comércio e obras Públicas (1869), Ministro da Justiça (1875), Diretor do Ministério dos Estrangeiros (1872), Deputado Provincial, Deputado Geral, Senador Vitalício pelo Estado do Rio Grande do Norte, e membro do Conselho do Estado. Além dessas passagens, representou o Brasil na Exposição Universal de Paris como comissário geral.

A elite política imperial era composta, segundo Carvalho, pelo Imperador, pelos conselheiros de Estado, pelos ministros, pelos senadores e deputados. Para o autor, dada à simplicidade da estrutura política do Império, os cargos formais de comando coincidiam com a capacidade efetiva de comandar. Não há, portanto, necessidade de se escolher entre uma 
definição "posicional" ou "decisional" de elite (CARVALHO, 1987, p. 43).

A partir da leitura de Carvalho entendemos os principais canais pelos quais circulavam os membros da elite, dentre estes Diogo Velho Cavalcante, reforçando a sua coesão do ponto de vista do seu treinamento profissional. Segundo Carvalho (1996), a estabilidade política do Império propiciou aos membros da elite longas carreiras políticas e, por consequência, uma ampla circulação geográfica em função dos cargos que ocupavam. Esta última conferiu ao grupo uma visão global do País, já que seus membros passavam por várias províncias no decorrer de suas carreiras, além de fortalecer a sua coesão em função do treinamento que a circulação propiciava (CARVALHO, 1987). Para Carvalho a especificidade da elite política imperial muito provavelmente não era devida à origem social de seus membros, prendendo-se muito mais à sua socialização pela educação, ocupação e treinamento político, o que Ihe teria garantido uma determinada concepção de Estado (p. 124).

Egresso do Lyceu Provincial da Parahyba do Norte, Bacharel, formado na Faculdade de Olinda, foi um dos pensadores da construção da estrada de ferro Conde D'Eu, que ligava Cabedelo a Alagoa Grande e pela extensão da linha telegráfica de Recife a Cidade da Parahyba. Além dos Relatórios e Pareceres elaborou um trabalho intitulado Notice generale sur les principales lois promulgues au Brésil de 1891 a 1894, uma monografia apresentando um resumo histórico dos primeiros anos do Brasil República (FERRONATO, 2014).

Ainda enquanto aluno do Curso de Direito, foi um dos redatores da revista Literária Alva, a mais importante revista literária da Parahyba do Norte, redigida na tipografia de José Rodrigues da Costa (PEIXOTO, 2017). Fizeram parte da redação da revista, além do Diogo Velho Cavalcanti d' Albuquerque, os redatores acadêmicos João da Costa Ribeiro, José Carlos da Costa Ribeiro, Olinto José Meira, Adelino Antônio de Luna Freire e Salvador Henrique de Albuquerque. Ou seja, nomes de forte atuação na política oitocentista.

Ao analisar o estado da instrução na Província da Parahyba do Norte no ano de 1860 a partir do relatório do diretor da Instrução Pública Diogo Velho Cavalcante d'Albuquerque de 1861, é possível apreender que uma das principais inquietações e problemas colocados pela diretoria de Diogo Velho naquele ano eram as constantes alterações existentes nas leis e regulamentos que regiam este setor que prejudicavam o objetivo de dar uma unidade instrucional pretendidos pelo referido Diretor. Segundo Gondra e Schneider (2011, p. 120) "os primeiros regulamentos de 1849 foram elaborados para atender a demanda organizativa, assumir a regulação e a fiscalização dessas cadeiras de primeiras letras". Como podemos perceber na fala abaixo:

Este assumpto
importantíssimo é
regulado actualmente pela
lei provincial n. 12 de 8 de
Agosto de 1860, que
suspendendo a execução
do Regulamento expedido
em 27 de Janeiro do
mesmo anno pela
Presidencia da Provincia,
restabeleceu a legislação
anterior com ligeiras
modificações. Vigora pois
O regulamento de 11 de
Março de 1852
(FERRONATO, 2015, p.
175).

O diretor de Instrução Pública, Diogo Velho Cavalcanti d' Albuquerque, indaga em sua fala a mudança da lei que regulamentava a instrução. Talvez, pela sua experiência enquanto Presidente de Província e político de várias esferas que discutia os caminhos em que a Instrução Pública, assim como outras pastas do serviço público deveriam prosseguir, encontrou argumentos para ressaltar o quanto a legislação da Província responsável pela educação estava longe de satisfazer o progresso intelectual da nação brasileira, quando enfatiza que,

$$
\begin{aligned}
& \text { Essa Legislação está bem } \\
& \text { longe de satisfazer as } \\
& \text { necessidades do mesmo, } \\
& \text { elevando-e a merecida } \\
& \text { altura, e encaminhando-o } \\
& \text { ao resultado grandioso de } \\
& \text { uma educação nacional, } \\
& \text { adoptada as nossas } \\
& \text { instituições, costumes, } \\
& \text { crença religiosa, aspirações } \\
& \text { e interesses materiaes. } \\
& \text { (FERRONATO, 2015, p. 175) }
\end{aligned}
$$

De forma bastante contundente, a opinião expressada pelo então diretor da 
Instrução Pública, Diogo Velho, busca transmitir, a ideias de que a nação brasileira precisa de uma educação consistente, nacional e única, tendo em vista, o progresso da civilização e sua uniformidade.

A actual organisação da instrucção publica, as matérias que a constituem, o methodo de diffundil-a, em vez de darem esse resultado, mostrão que, em quanto certo progresso intellectual, mesmo mal encaminhado, tem movimento ascendente em algumas classes, outas jazem em deplorável estado de ignorância. (FERRONATO, 2015, p. 175)

Isto leva-nos a inquietadora consequência de que a nossa civilização, segundo ele, é um edifício erguido na areia (FERRONATO, 2015, p. 175). Para ele, os problemas da instrução no Brasil estavam na base em que permanecia a construção da educação, a fragilidade da legislação, o constante retrocesso em torno da pasta educacional, corte de verbas, enfim, uma agitação que mesmo movimentando parte da sociedade para o caminho do progresso intelectual, a outra parte, encontra-se em "Estado deplorável". Para enfatizar estas questões em seu discurso ele lança a seguinte pergunta:

E pois, cumpre reagir contra o mal, estancando-lhe a fonte. A instrucção é um meio indispensável de progresso, sabe todo mundo esse axioma do senso commum, e o baptismo da luz, na prhase Hermenier, deve ser lançada na fronte do povo. Mas o que fazer? (FERRONATO, 2015, p.175)

Para ele, o caminho mais profícuo estava no papel do estado em organizar e distribuir convenientemente o ensino comum a todos os homens. Uma organização central para a educação, um projeto único para todas as Províncias que possibilitasse o uso das matérias indispensáveis para o desenvolvimento do conhecimento do ensino superior. Assim como, um ensino especial pautado na necessidade e a circunstâncias de cada localidade. Uma educação com uma direção central/nacional, capaz de fazer prevalecer um sistema de ensino forte, pois,

A diversidade de leis como conseqüência a diversidade de methodos, princípios, livros, etc.; isto é, a anarchia- e a instrucção entregue a anarchia póde ser um activo dissolvente, ao passo que a sua unidade é sem duvida e meio mais efficaz para inspirar a um povo o sentimento do fim commum e da solidariedade nacional (FERRONATO, 2015, p. 175).

Portanto, Diogo Velho Cavalcanti $d^{\prime}$ Albuquerque considerava a alternância de leis que regulamentavam a educação um mal para a Nação. Segundo ele, é:

[...] preciso que o poder supremo do estado, tenha toda e qualquer iniciativa para a ação de aberturas de matérias de ensino. Que essas cadeiras estejam entrelaçadas a um projeto educacional central e nacional, igual para todos os homens, que sejam inspecionados, que se difundam com homogeneidade os conhecimentos assim, preparando o cidadão brasileiro para o exercício de todos os seus direitos e deveres. Em quanto não é possível dar essa direcção geral á instrucção, deveria a Provincia harmonisar a de seus filhos com a das outras mais adiantadas, e regeneral-a da decademcia em que vae. (FERRONATO, 2015, p. 176).

\section{Professores instruídos ou autodidatas?}

Um dos questionamentos de Diogo Velho, membro do grupo conservador na Província, em seu relatório girava em torno da formação dos professores e como o sistema político abordava as questões de formação em torno desses profissionais. O diretor salientava que as questões da formação docente eram algo 
urgente e necessário e que era preciso instituir o uso da Pedagogia tanto a quem ensina quanto a quem aprende.

Entende-se a partir disso que em sua visão era necessária a implementação na Província ou nas Províncias das Escolas Normais ou dos cursos normais para uma melhor formação dos professores. No que se refere a estas instituições, a primeira Escola Normal brasileira foi criada em Niterói, Rio de Janeiro, no ano de 1835. Esse curso tinha o objetivo de formar professores para atuarem no magistério de ensino primário e era oferecido em escolas públicas de nível secundário.

A partir da criação da escola no Município da Corte, em 1874, várias Províncias criaram Escolas Normais a fim de formar o quadro docente para suas escolas de ensino primário. Desde então, o movimento de criação de Escolas Normais no Brasil esteve marcado por diversos movimentos de afirmação e de reformulações, mas não obstante a isso, o Ensino Normal atravessou a República e chegou aos anos 1940/50, como instituição pública fundamental no papel de formadora dos quadros docentes para o ensino primário em todo o país (VILLELA, 1992).

Em seu relatório o Diretor da Instrução propõe realizar a formação dos professores da Província nas dependências do Liceu Provincial (ARAÚJO, 2010; FERRONATO, 2012). No entanto, a implantação da Escola Normal se deu apenas no ano de 1884, depois de muitas solicitações e debates políticos como informa Araújo (2010).

O Diretor levanta a crítica em seu relatório sobre a formação de professores, uma vez que para concorrer ao cargo de professor não era necessário estar habilitado pela Escola Normal. Nesse sentido ele afirma:

A primeira necessidade é, pois, instituir a pedagogiacrear o professorado-acerca do que temos; nem escola normal, propriamente dita, nem escola modelo conforme a pratica de alguns paizes da Europa, onde se concede essa cathegoria ás escolas mais bem regidas, e que melhores resultados dão, nem as classes normaes, systema usado a principio na Hollanda, e hoje até em algumas de nossas
Provincias,-que consiste em dar aos alumnos das escolas communs, que mais aptidão e vocação manifestão, lições especiaes sobre a pedagogia, e principalmente em empregal-os nos exercícios das classes á principio como alumnos mestres, e depois como adjuntos, até que passão á professores effectivos, etc [...] (FERRONATO, 2015, p. 176).

Como forma de chamar a atenção para este problema da formação dos professores Diogo Velho estaria expondo à sociedade política que o sistema era o "mas acomodado, o mas frágil", (FERRONATO, 2015, p. 176) e que as circunstâncias vividas pelo nação brasileira em torno do que respaldava a Instrução Pública e a formação do professorado não caminhava em torno do progresso.

Estou convencido de que, em quanto não for attendida essa primeira e mais urgente necessidade, e não se dar ao professorado positivas garantias de bem ser material, importância social, e segurança de seu futuro, todas as reformas effectuadas, e por effectuar, não passarão de alterações de formas, sem alcance nem vantagem (FERRONATO, 2015, p. 176)

Ainda neste relatório, Diogo Velho enfatizava a questão da escassez das cadeiras de ensino para o sexo masculino, que para ele seria um problema derivado das demissões, remoções e jubilações de professores daquela Província, e destaca que naquela ano teriam sido jubilados os seguintes professores: Joaquim Casado de Almeida Nobre, Bazilio Antônio da Costa, Francisco Ignácio da Silva, Francisco Herculano de Medeiros, José Martins da Silva, José Torquato de Sá Cavalcanti, Padre Antonio Fernandes Teixeira, Francisco Pulquerio Gonsalves de Andrade. Outros teriam sido demitidos: Francisco Augusto Neiva Junior e Antonio Felix de Souza Pontes. Já outros, foram removidos: Prudente Gabriel da Veiga Pessoa Junior, Tiburcio Valeriano da Silva Dourado, Manoel Brayner, Cyro Deocleciano 
Ribeiro Pessoa. Tais remoções causariam um problema para o desenvolvimento da instrução na Província. Enfim, o resumo desse movimento teve o seguinte resultado.

Provimentos
effectivos.............9
Nomeações, interin
as..........................
Jubilações.............8
Remoções.............7
Dimissões .............4
(FERRONATO, 2015,
p. 179)

O cerne dos problemas da instrução na Província, que carecia de recursos devido a sua situação econômica estava, segundo o Diretor, no fato de os professores serem mal instruídos pedagogicamente, visto não existir uma Escola ou um curso normal para realizar esta formação, e na baixa renumeração dos professores. Tais problemas estariam contribuindo para o não progresso da Nação que estava se formando.

Ainda neste relatório que reputamos ser um dos documentos mais completos de análise da instrução na Província, no período aqui analisado podemos perceber anotações sobre a falta de uma organização da instrução pública e o entendimento por parte do Diretor de que a instrução pública era um dos mais "importantes interesses da ordem provincial, assim como a municipalidade, a polícia, a guarda nacional, a justiça" (PARAHYBA DO NORTE, Relatório. In: FERRONATO, 2015, p. 100).

Em sua crítica à organização da instrução na Província o diretor chama a atenção para uma falta de uniformidade no ramo da educação no que se refere à formação, aos níveis de ensino, às disciplinas e ao tempo escolar. Para reafirmar a necessidade do reordenamento e organização da instrução Diogo Velho como referência J. Ganrier que diz:

$$
\begin{aligned}
& \text { A instrucção deve, estar } \\
& \text { em relação " com a } \\
& \text { posição social do } \\
& \text { individuo, deve preparal-o } \\
& \text { para a sua profissão e } \\
& \text { "para a sua condicção.- } \\
& \text { Uma instrucção mal } \\
& \text { dirigida, } \\
& \text { necessariamente } \\
& \text { incompleta e desvia do } \\
& \text { seu caminho, e prepara- } \\
& \text { lhe rudes provações, } \\
& \text { amargas decepções» }
\end{aligned}
$$

(FERRONATO， 2015, p. 176).

Nesse sentido, para ele seria importante que a instrução seguisse simultaneamente com uma educação religiosa e moral, a fim de formar bons cidadãos. No que se refere à organização da instrução da Província da Parahyba do Norte na década de 1860, pelos dados apresentados no relatório analisado temos 69 aulas do ensino primário, sendo que destas aulas 64 eram do sexo masculino, com 1697 alunos, e 15 do sexo feminino, com 352 meninas. As matérias que constituem o ensino primário para o sexo masculino, estão organizadas conforme o regulamento em vigor da instrução pública da Província da Parayba. Entre elas, leitura e escrita, aritmética até proporções, doutrina cristã, elementos de gramática da língua nacional, e com especialidade a ortografia. Seguindo das noções gerais de geometria prática sem demonstrações. As meninas, todavia, aprendiam prendas domésticas.

Diante do ensino aplicado a instrução primária, o então diretor Diogo Velho questionou o mínimo de desenvolvimento intelectual que essas matérias poderiam fornecer aos cidadãos, assim como a falta de interesse na maior parte dos rapazes do interior em estudar. Em outras localidades, o interesse pelo desenvolvimento era mais atrativo. Para conciliar essa tendência de interesse oposta,

O meio de conciliar estas
tendências oppostas é a
divisão do ensino em dous
grãos. Nas cadeiras do 1o
ensinar-se-hão as referidas
matérias, limitando-se os
elementos de calculo até
frações ordinarias,
supprimindo-se as noções
de geometria pratica, e
dando-se mais
desenvolvimento a a
instrucção religiosa. As
cadeiras do 2o grão, só
para o sexo masculino,
deverão ser distinctas das
do 10, e substituirão essas
inúteis aulas de latim do
interior (FERRONATO,
2015, p. 179).

Para ele o papel central de um legislador estaria voltado a dirigir e encaminhar o povo a seu desenvolvimento enquanto cidadão. Para tal, 
deveria usar da "educação e instrução" para civilizar. Para que esse caminho seguisse de maneira uniforme e ágil, era preciso que as capitais ficassem com o respectivo ensino do liceu, e das escolas normais, das quais sairiam os futuros professores.

Nas cadeiras do interior estariam inseridas escrituração e contabilidade mercantil, além das noções gerais de economia rural que estabelecessem um bom desenvolvimento a agricultura, tendo em vista que nos Oitocentos o Brasil era um país agrícola. Nesse sentido, Digo Velho afirmou: "Atenda-se que não quero tanto para a nossa Parahyba. Reclamo apenas algumas d'essas escolas, no intuito de fornecerem-se conhecimentos profissionaes segundo as localidades, de modo que a instrucção seja industrial e commercial nas cidades, e agrícola no interior". (FERRONATO, 2015, p. 180).

Tendo em vista algumas pontuações a respeito do ensino primário nas quais, o então Diretor de instrução pública mencionou algumas delas: a falta da frequência constante dos alunos e o desinteresse da família pela inserção de seus filhos a educação. $O$ diretor apontou os problemas:

É uma triste verdade que o ensino primário entre nós, além de insufficiente, está muito pouco diffundido. Para este resultado concorrem, não só os deffeitos de sua organização, mas também as circumstancias peculiares de um paiz ainda novo, cujapopuação se acha muito disseminada, e cujas communicações, quer geraes quer vicinaes, são em regra difficilimas, e ainda mais a nenhuma conta em que a instrucção é tida (FERRONATO, 2015, p. 180).

Em torno do ensino secundário, composto de línguas Latina, Francesa e Inglesa, além de Aritmética, Álgebra até equações do 20 grau, Geometria, Trigonometria Retilíneas, Geografia, Cronologia, História universal, com especialidade em Geografia e História do Brasil, Filosofia Racional e Moral, Retórica e Poética, Diogo Velho ressalvou o número de cadeiras existentes na Província da Paraíba para esse ensino. Para o então diretor, essa instrução auxiliaria num desenvolvimento intelectual com um maior cuidado que o ensino primário. Essa cadeira foi em 1860 frequentada por 86 alunos.

A cadeira de francês, que era ministrada junto com a de inglês, foi desvinculada e posta a concurso no dia 2 de junho de 1860 , e foi regida pelo professor efetivo João Antônio Marques. Para o então diretor, a separação acarretaria o maior benefício ao desenvolvimento da instrução. No entanto, as discussões em torno dos caminhos que seguia o ensino secundário adotavam:

A idéia de há muito discutida de converter o Lyceo em um internato, parece comndenada a não ter effectiva realização[...] O novo regulamento da Instrucção publica, que consignava esse melhoramento está suspenso, e a crise financeira por que passa a Provincia retardará indefinadamente a sua execução[...] 0 actual Lyceo está decadente; e muito concorre para esse resultado o curto lapso de tempo marcado para a validade dos exames de preparatórios nas faculdades de direito. O estudante que quer matricular-se e que em dous annos deve prestar esses exames, prefere ir alinhar-se as respectivas matérias com os professores que tem de examinal-os (FERRONATO, 2015, p. 181).

Assim colocando em pauta as discussões secundárias, Diogo Velho Cavalcanti $d^{\prime}$ Albuquerque, ressalva a necessidade de tornar o ensino do Liceu em um internado, que possibilitasse esse estabelecimento se tornar o meio, mais conveniente e útil para o desenvolvimento da mocidade, da cultura, educação e da nação brasileira.

\section{CONSIDERAÇÕES FINAIS}

O processo da construção historiográfica está relacionado à importância da compreensão da análise das fontes investigadas. Sendo assim, é 
cabível ressaltar que o estudo da História da Educação, usando como base documentos oficiais, tais como relatórios pertencentes a vários setores administrativos, é de extrema importância para a compreensão das discussões vigentes de uma determinada época, sobre um determinado fato.

Sendo assim, ressaltando a fala de Diogo Velho Cavalcanti d' Albuquerque, então diretor de instrução pública da Província da Paraíba do Norte, em 1861, foi possível perceber que seu pensamento estava voltado à construção da instrução paraibana, no que se refere ao processo de "instruir para civilizar". Para isso, o então dirigente do século XIX expôs a alternância da legislação e seus males.

Seguindo seus pensamentos foi possível perceber que o dirigente refletiu com inquietação os caminhos que a instrução pública estava por seguir, diante do direcionamento que a legislação vigente à época apontava sobre a instrução. Segundo o diretor, poderia não obter-se um bom desempenho da construção intelectual da sociedade do povo brasileiro.

Além desses relatos, lançou questões em torno da formação de professores e do espaço apropriado para construir esses profissionais que se tornariam a base para o bom desempenho da instrução. Em torno dos relevantes apontamentos, o então diretor de instrução pública enfatiza o quanto é importante instruir e reconhecer esses profissionais como o mais profícuo da nação.

Para além dos questionamentos em torno da formação do professorado, estavam os relevantes posicionamentos em torno do ensino primário e secundário. É possível perceber que para Diogo Velho a fragilidade em torno do ensino inicial do cidadão (ensino primário), era extremamente prejudicial ao seu desenvolvimento intelectual, pois defendia a construção de uma educação uniforme, relevante e eficaz. O ensino secundário estava andarilhando a um caminho com maior eficácia, tendo em vista, que era a partir dele que o cidadão era preparado para ingressar nas universidades. No entanto, o dirigente, questiona a forma na qual, as disciplinas e conteúdos eram aplicados e administrados.

Além disso, o registro documental demostra as principais preocupações relativas à instrução pública que perpassaram todo século $X I X$. O alcance das discussões que se fizeram presentes em todo período Oitocentista, as perguntas, análises e reflexões nos levam a refletir, até os dias atuais, a importância do pensamento de quem faz a educação ou a dirige.

\section{REFERÊNCIAS}

ARAÚJO, Rose Mary de Souza. Escola Normal na Parahyba do Norte: movimento e constituição da formação de professores no século XIX. 2010. 319f. Tese (Doutorado em Educação) - Centro de Educação, Universidade Federal da Paraíba, João Pessoa, 2010.

CARVALHO, José Murilo de. Os bestializados: o Rio de Janeiro e a República que não foi. São Paulo: Companhia das Letras, 1987.

FARIA FILHO, Luciano Mendes de. Editoração, sociabilidades intelectuais e mediação cultural. In: Ângela Maria Castro Gomes; Patrícia Santos Hansen (Org.) Intelectuais Mediadores. Rio de Janeiro: Civilização Brasileira, 2016, v.1, p. 366402.

FERRONATO, Cristiano. A instrução Pública na Parayba do Norte discursos, falas e relatórios de presidentes da província (1837-1889). Vitoria: SBHE/Edunit/Virtual Livros, 2015. Disponível em http://www.sbhe.org.br/e-books/sbhe-

paraiba/sbhe-02/mobile/index.html Acesso em: 28 jul. 2018.

GONDRA, José Gonçalves; SCHNEIDER, Omar. Educação e instrução nas províncias e na Corte Imperial: (Brasil, 1822-1889). Vitória: EDUFES, 2011. (Coleção Horizontes da pesquisa em história da educação no Brasil).

FERRONATO, Cristiano. Das aulas avulsas ao Lyceu Provincial: as primeiras configurações da instrução secundária na província da Parayba do Norte (1836-1884). Aracaju: EDISE, 2014.

MATTOS, Ilmar Rohloff de. O tempo Saquarema. São Paulo: HUCITEC; Brasília: INL, 1987.

PEIXOTO, Thayná Cavalcanti. José Rodrigues da Costa: Um Tipógrafo na Cidade da Parahyba 1848-1866. João Pessoa: Mídia Gráfica, 2017.

RESENDE, Fernanda Mendes; FARIA FILHO, Luciano Mendes. História da política educacional em Minas Gerais no século XIX: os relatórios dos presidentes de província. Revista Brasileira de 
História da Educação, Campinas, n. 2, p.81-115. jul./dez. 2001.

SAVIANI, D. História das Ideias Pedagógicas no Brasil. Campinas: Autores Associados, 2007.

VILLELA, H. O. S. A primeira Escola Normal do Brasil. In: Clarice Nunes. (Org.). 0 passado sempre presente. São Paulo: Cortez, 1992, p. 1742.

Submetido: 15/03/2019

Correções obrigatórias: 15/04/2019

Aceite final: 29/04/2019 